\title{
Detecting and Mitigating Rod Drive Control System Degradation in Westinghouse PWR's
}

\author{
W. Gunther and K. Sullivan
}

\begin{abstract}
A study of the effects of aging on the Westinghouse Control Rod Drive (CRD) System was performed as part of the U.S. NRC's Nuclear Plant Aging Research (NPAR) Program [1], [2]. For the study, the CRD system boundary includes the power and logic cabinets associated with the manual control rod movement, and the control rod mechanism itself. The aging-related degradation of the interconnecting cables and connectors and the rod-position-indicating system also were considered. This paper presents the results of that study pertaining to the electrical and instrumentation portions of the CRD system, including ways to detect and mitigate system degradation.
\end{abstract}

\section{BACKGROUND}

$\mathrm{T}$ HE control rod drive mechanisms (CRDM) are located on the dome of the reactor vessel and are mechanically coupled to their associated rod cluster control assemblies (RCCA's) located directly below. The primary purpose of the CRDM is to physically position the control rods within the core in response to electrical current command pulses generated by the rod control system. As illustrated in Fig. 1, the major components associated with the motion of each control rod are the three coils (movable, lift, and stationary), the power and logic cabinets, and the interconnecting cables and connectors. In addition, a subsystem of electrical components provides the position of each control rod. Each of these major subcomponents is briefly described.

Coil Stack Assembly: The coil stack assembly includes a coil housing, an electrical conduit and connector, and three electromagnetic operating coils: the stationary gripper coil, the movable gripper coil, and the lift coil. Two lead wires per coil are carried through a conduit to the top of the pressure housing, where they terminate in a single six-pin electrical connector.

Power Cabinets: The power cabinets contain solid-state electronic equipment, which converts $260 \mathrm{~V}$, three-phase ac power to dc power supplied to the coil stack assembly.

Logic Cabinets: The logic cabinet contains the circuitry for low-level electronic signals, which are necessary to develop the switching signals required for proper operation of the power cabinets. Relays required to drive equipment that

Manuscript received July 10, 1991. This work was performed under the auspices of the U.S. Nuclear Regulatory Commission. This paper was presented at the 1990 Nuclear Science Symposium.

The authors are with the Department of Nuclear Energy, Brookhaven National Laboratory, Upton, NY 11973.

IEEE Log Number 9103871

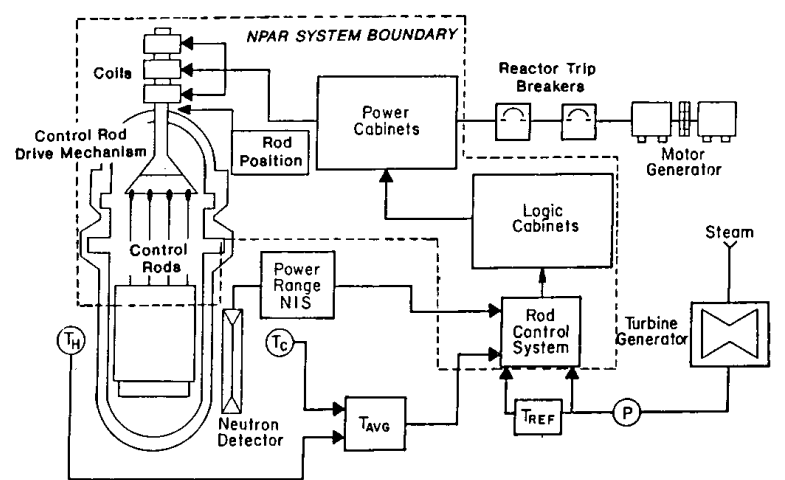

Fig. 1. CRD system block diagram.

is external to the system, such as the plant computer and annunciators, are also located in the logic cabinet.

Rod Position Indication Subsystem: Westinghouse PWR's have two independent systems to monitor the position of control rods within the core. One system obtains information from detectors that are mounted on each CRDM, and therefore represents the actual position of each control rod within the core. The second system counts the number of steps of rod motion that have been demanded by the rod control system. Its indication represents the position where the rods should be.

\section{ASSESSMENT OF THE OPERATING EXPERIENCE}

The review of the operating experience of this system as documented in the Licensee Event Reports (LER's), the Nuclear Plant reliability Data System (NPRDS), and the Nuclear Power Experience (NPE) databases has resulted in the following observations. (These sources provided an average of 30 unique failure events per year over the last ten years.)

- The majority of the reported failures have occurred in the electrical area (Fig. 2), namely, the power and logic cabinets and the rod position indication subsystem.

- Approximately $30 \%$ (i.e., 40 of 125 LER's) of the failures have resulted in a rod drop. This event usually challenges the reactor protection system which initiates a reactor trip.

- Several failure modes, such as rod position drift and power cabinet overheating, are common to multiple plants. This could indicate the need for generic resolutions of these system problems. 


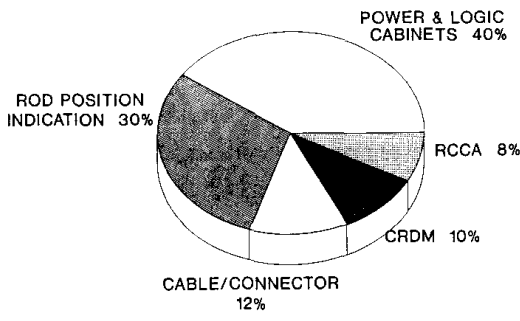

Fig. 2. CRD system failures.

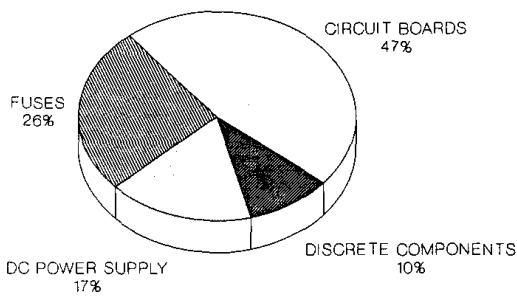

Fig. 3. Failures in the power and logic cabinets.
- The normally energized stationary gripper coils have experienced a much higher failure rate (order of magnitude) than the movable gripper and lift coils. Thermal stress from ohmic heating could be an important contributor to coil degradation.

- Certain circuit boards in the power cabinet are more susceptible to failure than others located in the same cabinet. The firing circuit card is an example, with about $20 \%$ of the reported failures attributed to it. This card contains thyristors which are susceptible to damage from overheating.

- Approximately $30 \%$ of the combined failures in the power and logic cabinets were associated with the fuse protection circuits, including the fuse and its associated mounting hardware (fuse clip). Several instances of observed fuse degradation, such as "fatigue" or "normal end-of-life," were found in the operating experience data.

- The cables and connectors, which link the power cabinets to the CRDM's, accounted for about $12 \%$ of the system failures, with connector problems being the dominant contributor. Mechanical wear of the plug contacts and corrosion in the area of the connector pin mating surfaces were the degradation mechanisms identified. All of the reported failures occurred at plants in operation for more than five years.

A further review of the data was performed to evaluate the distribution of failures within the power and logic cabinets and to identify any dominant failure trends in the subcomponents. Fig. 3 shows the results of this review; printed circuit logic cards are the most frequently failed component, followed by fuses, dc power supplies, and discrete components.

An additional sort of the data also identified cable connectors and receptacles, located at the CRDM coil stack assembly, to be the dominant cause of failures within this section of the CRD system. The primary degradation mechanisms of coil stack connectors include mechanical wear of the plug contacts and corrosion in the area of the mating surfaces of the connector in. The reported failures occurred at plants that were in operation for more than five years. This observation may indicate a need for improving the current inspection methods or the frequency of inspection since wear-related problems of electrical connectors are due to repeated connections over time. Westinghouse has changed to a different connector design in new plants to address this issue.

Cable failures were also identified in the data, including failures of electrical penetration modules. Subsequent analysis identified mechanical stress as the root cause of insulation degradation. This caused the conductor to corrode due to the intrusion of moisture. Age-degraded cable insulation caused a short circuit between coil leads in a section of cable located near the CRDM. The faulted cable, which was estimated to be eight years old, caused the stationary coil fuse to open, resulting in a dropped control rod.

Of the data reviewed which described failures of the coil assembly, a large majority was the result of a failure of the stationary gripper coil, which is normally energized to hold its associated RCCA in a desired position. Deenergizing the stationary coil at any time during plant operation, other than those times required to perform a rod insertion or withdrawal stepping sequence, will result in dropped rods which may cause an automatic trip of the reactor. All reported failures of stationary gripper coils occurred in coils with more than ten years of operating life. The predominance of failures of stationary coils, when compared to other coils of this subassembly, may be due to aging-related degradation of the stationary coil's electrical insulation. This increased level of thermal stress could be derived from ohmic heating of the coils during long-term energization.

The distribution of reported component failures within the rod-position-indication system is shown in Fig. 4. As indicated in this figure, calibration drift was the leading cause of failure (44\%). Problems related to instrument drift appear to be affected by temperature variations that are induced in the CRDM during the heatup of the primary system. Such temperature fluctuations are suspected to cause a corresponding variation in the thermal equilibrium of the linear variable differential transformer (LVDT) detector coils, which are concentrically mounted on the CRDM pressure housing.

Table I summarizes the review and analysis of operational experience data related to the Westinghouse Control Rod Drive System, and briefly describes the failure modes, causes, and mechanisms for selected subcomponents.

\section{Detecting and Mitigating Degradation}

An evaluation of inspection, surveillance, monitoring, and maintenance activities which cquld be used to detect and mitigate the degradation of electrical and electronic components within the control rod drive system was accomplished with support from industry. Fifteen plants representing ten utilities responded to questions about the coil stack assembly (lift, stationary gripper, and movable gripper coils), the cable and connector assemblies for the coils, and the rod-positionindication subsystem wiring. The preventive maintenance on this equipment (which is located inside containment) is performed during refueling outages, and it consists primarily of insulation resistance checks (megger), conductor resistance 


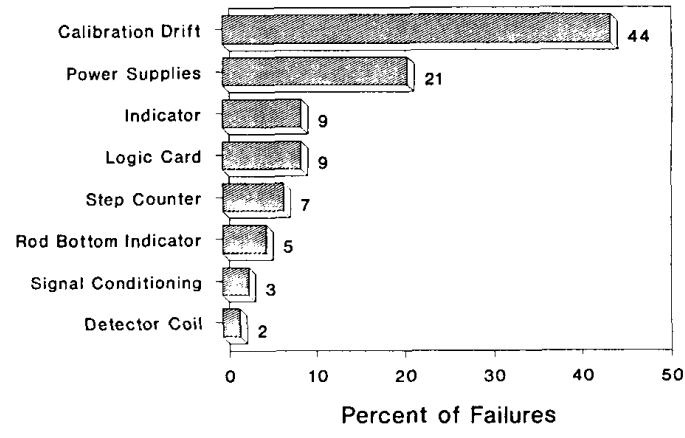

Fig. 4. Rod-position-indication system failure causes.

tests, and visual inspections for signs of degradation such as wear, corrosion, or looseness.

Of a more unique nature is the monitoring of coil stack degradation by three of the plants. Coil traces of the in and out control rod motions are taken before startup, following a refueling outage. This technique can be performed at any time during operation as well to detect changes in coil characteristics. Two plants also perform an inspection of all electrical watertight seal connections during each refueling outage.

Table II summarizes the preventive maintenance for the CRD system electrical components within containment. It should be noted that all but one of the plants perform some form of electrical testing on the CRDM and rod position coils, and routinely inspect the electrical connectors for any signs of degradation.

The power sources and logic necessary for properly operating the system are generally located outside of containment. This equipment is, therefore, accessible to personnel during power operation. This portion of the system is continuously monitored during operation to a certain degree through sensors which communicate with annunciators in or near the control room. Abnormal conditions in the power supply output, for instance, produce an alarm which would result in corrective actions. A unique practice among the surveyed plants exists at two of the plants. Their preventive maintenance program includes replacing all of the $10 \mathrm{~A}$ fuses of the stationary and moveable gripper coils at a three-year frequency. Two other plants replace selected control fuses in the logic cabinets every refueling outage. This replacement practice mitigates the effects of aging, which may cause the fuses to prematurely fail.

The preventive maintenance for CRD system components outside of containment are summarized in Table III.

The survey also asked for the utility's opinion regarding the monitored parameters, tests, or inspections which are most important for assuring the operational readiness of the CRD system. The results clearly reveal the opinion that testing which is required by the technical specifications is useful for determining system performance. Other favorable means for determining and maintaining the operational readiness are through circuit tests, calibrations of components, and thorough visual inspections.
Inspection, Surveillance, Monitoring, and Maintenance (I, S, M\&M) Techniques

The I, S, M\&M techniques which are applicable to the CRD system were evaluated to determine those that could be effective in detecting aging degradation in an incipient stage. Visual- and instrument-aided methods, including on-line techniques, are discussed with consideration for practicability.

The Japanese developed a system which detects degradation in the CRDM through on-line analysis of current signals and noise that is generated during rod motion [3]. As shown in Fig. 5, the system analyzes five parameters for each CRDM: current data from three coils (lift coil, movable gripper coil, and stationary gripper coil); sound data, which can be monitored by an accelerometer mounted on the top of the CRDM pressure housing; and a logic signal generated from the rod drive timing circuit.

The movement of the magnetic pole pieces through the magnetic field produced by the energized coils induces a current which appears as a dip on the coil current plot. By analyzing the degree of dip on each current curve together with the sound data, information on drive rod, coil, and magnet performance is obtained. Input to preventive maintenance needs on the CRDM is achieved by this system. The system has on-line capability which permits continuous monitoring of the rods during normal power operation.

A second detection technique which has potential application in the CRD system is the Electronic Characterization and Diagnostics System (ECAD) which uses electronic instrumentation to characterize circuit continuity and insulation integrity. It may be possible to detect degrading circuits by examining several common electrical parameters such as coil resistance, insulation resistance, capacitance, and dissipation factor. The intent of the inductance in conjunction with the measurement of dc resistance is to identify the condition of the coil. Moisture intrusion has been a common cause of cable and connector degradation. ECAD uses the capacitance and dissipation factor to determine the presence of moisture. As moisture penetrates into a cable, the dissipation factor and capacitance increase.

\section{ConClusions AND RECOMMENDATIONS}

The control rod drive system used in Westinghouse pressurized water reactors performs functions which are important to plant safety and availability. These are to: 1) shut down the reactor in the event of an unsafe condition, as sensed by the reactor protection system; 2) provide small changes in reactivity in response to plant load variations; and 3) continuously indicate control rid positions. Nuclear power plant operating experiences and survey responses from 15 nuclear plants are cited in support of the conclusions and recommendations presented in this paper. Further analysis of the methods and techniques for detecting and mitigating degradation is expected to yield testing and maintenance practices which are technically feasible and practical.

Based on the results of this study, the following components of the Westinghouse CRD system have exhibited degra- 
TABLE I

SumMary OF Operating EXPERIENCE

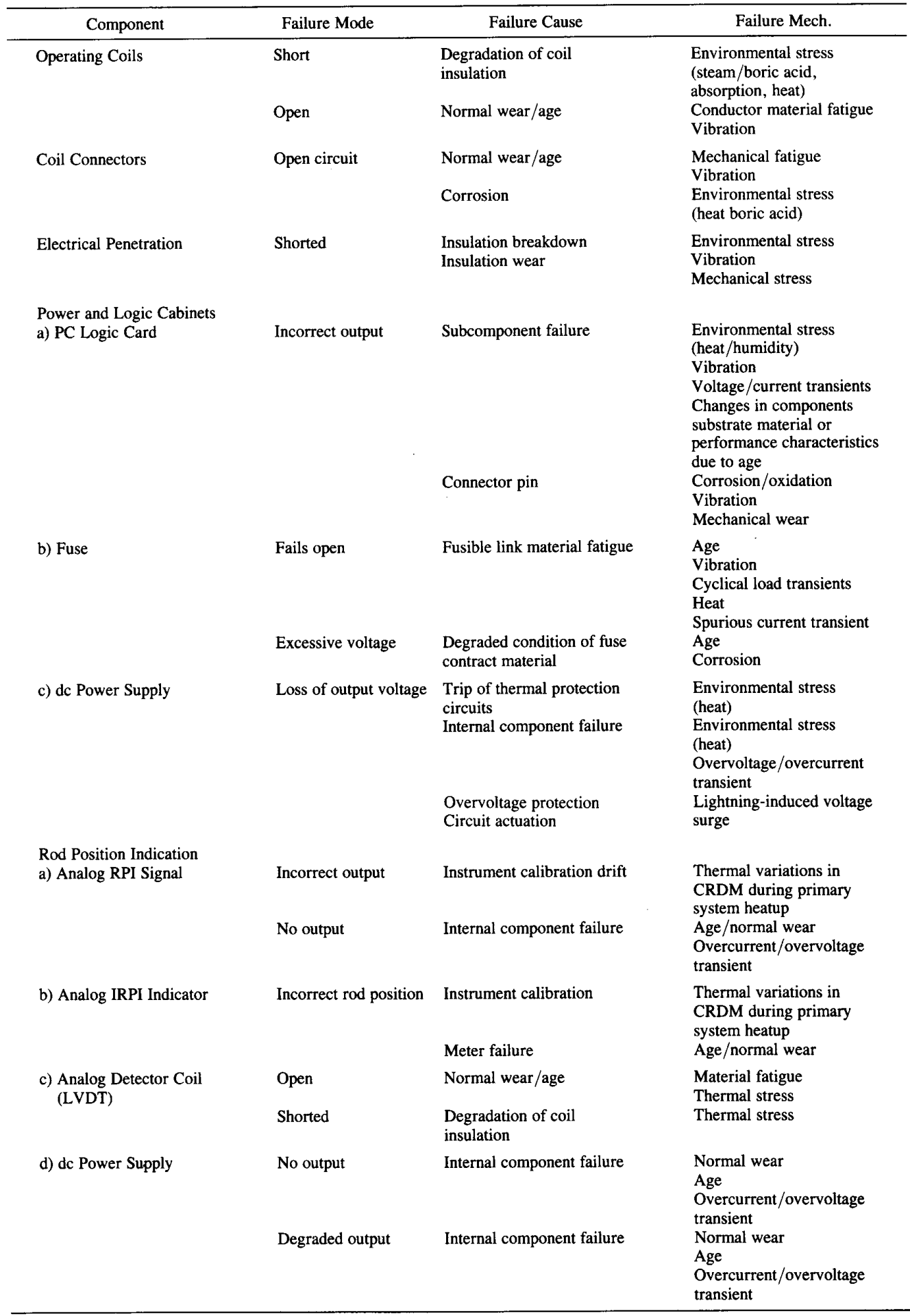


TABLE II

Preventive Maintenance Practices for Electrical COMPONENTS Within CONTAINMENT

\begin{tabular}{llc}
\hline \multicolumn{1}{c}{ Component } & \multicolumn{1}{c}{ Practice } & $\begin{array}{c}\text { Number of Plants } \\
\text { Involved and } \\
\text { Frequency }^{\text {a }}\end{array}$ \\
\hline Coil Stack Assembly & Insulation resistance & 7 \\
& Coil resistance & 14 \\
& Coil timing signature traces & 4 \\
Cable & Polarity check & 3 \\
Connectors & Insulation resistance & 7 \\
Rod-Position-Indication & 6 \\
Subsystem Wiring & Visual & 14 \\
& Inspect for tightness & 2 \\
& Visual & 4 \\
& Resistance measurements & 10 \\
& Insulation resistances & 3 \\
\hline
\end{tabular}

${ }^{a}$ All frequency intervals are refueling outage.

TABLE III

Preventive Maintenance Practices for Components OuTSIDE OF CONTAINMENT

\begin{tabular}{llc}
\hline \multicolumn{1}{c}{ Components } & \multicolumn{1}{c}{ Practice } & $\begin{array}{c}\text { Number of Plants } \\
\text { Involved and } \\
\text { Frequency }\end{array}$ \\
\hline Cables, Connectors, and & Insulation resistance & 7 \\
Terminations & Resistance check & 3 \\
Power Supplies & Visual inspection & 3 \\
& Calibrate protective devices & 5 \\
& Vendor refurbishment & 1 \\
& Functional test & 8 \\
Control/Logic Cabinets & Visual inspection & 5 \\
& Vendor refurbishment & 4 \\
& Replace fuses & $4-3$ years \\
& Measure cabinet temperature & 4 \\
& Timing/functional test & 2 \\
\hline
\end{tabular}

${ }^{a}$ All PM intervals are fueling unless specifically stated otherwise.

dation worthy of attention. These components, and the primary degradation mechanism affecting them, are

1) cable-insulation degradation

2) coils - insulation degradation

3) rod position indication detector-calibration drift

4) fuses - fatigue

5) power electronics-overheating.

Some of these components are not classified as "safety-related." However, because each can contribute to a rod block, rod drop, uncontrolled reactivity change, or tech spec violation, they are considered to be important to plant safety and availability.

The detailed review of the design of the Westinghouse CRD system, supplemented by the results of the industry survey, led to several findings related to degradation, which could be attributed to deficiencies in design in the CRD system or its interfaces.

1) Several utilities have experienced CRD system cable insulation or jacket material degradation sufficient in magnitude to justify replacement of these cables. This degradation is attributed to the inability of the cable system to withstand the high temperatures experienced in the upper head region.

2) Modifications to the cooling of the power and logic cabinets has been necessary at several plants. Temperatures

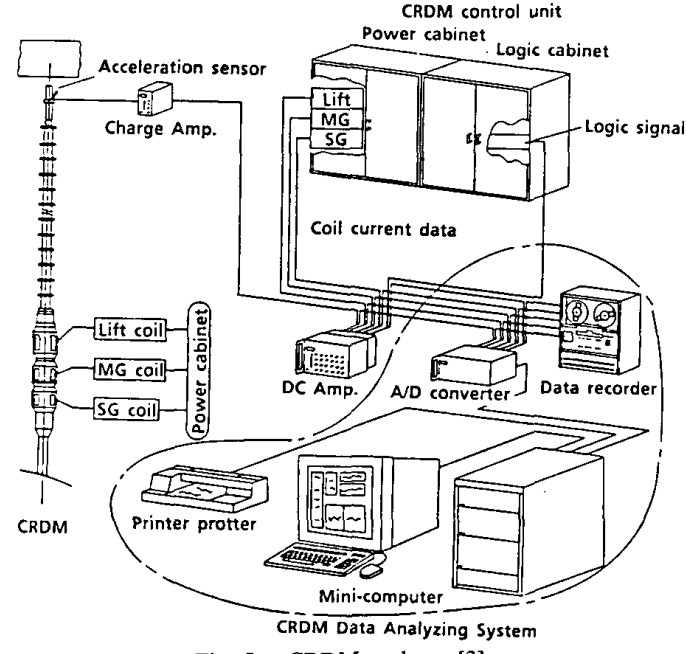

Fig. 5. CRDM analyzer [3].

as high as $125^{\circ} \mathrm{F}$ have been recorded in the cabinets. This will deleteriously affect many of the components, which are typically designed for $90^{\circ} \mathrm{F}$. The temperature of the cabinet is largely dependent on the ambient temperature in the area.

3) The number of connector problems in the upper head region due to moisture ingress or contaminations from borated water leakage indicates the need for a more substantial connector design. The stresses from this relatively severe environment appear to be underestimated.

4) The rod drop timing test is required to be performed once per cycle, in accordance with the plant technical specifications. Pulling this fuse to perform a rod drop test reduces the force between the fuse clip and the fuse, which has resulted in spurious open circuits and subsequent rod drops. The design should include a more permanent means for satisfying this required testing.

5) A positive aspect of the Westinghouse CRD system design is that it contains sensors which detect certain component failures. An urgent alarm, which results in a rod block, or a nonurgent alarm, indicating a loss of redundancy, provide an important input to the control room operators.

The review and evaluation of current maintenance and available inspection and monitoring methods have resulted in the following conclusions.

1) Preventive maintenance practices vary substantially from one plant to another, with some plants relying on the tech spec required testing to provide indication of system degradation.

2) Most preventive maintenance resources are applied to electrical components within the containment.

3) Based on the favorable responses from the utility survey, it is concluded that tech spec required activities (rod drop timing test and rod exercise) are beneficial in determining the operational readiness of the system.

4) The complexity of the system logic warrants specific procedures and detailed training for the personnel associated with maintaining it. It could not be concluded from the operating experience data or the results of the survey that this area is adequately addressed. 
To more effectively detect and mitigate the effects of aging in the Westinghouse control rod drive system, it is recommended that changes be made in the areas of design, maintenance, and monitoring. Mitigation of the effects of aging may be successfully addressed through changes to the system design. The goals of these modifications are to reduce or eliminate the stresses which contribute to aging degradation, or improve the materials to better withstand the existing stressors.

\section{Ventilation}

The ventilation systems in the upper head region and in the area where the power and logic cabinets are located should be modified to maintain lower ambient temperatures. It is important that operating personnel be made aware of unsatisfactory conditions so that prompt action can be taken. Maximum temperatures of 150 and $80^{\circ} \mathrm{F}$ for these two areas are reasonable design goals for the ventilation systems. Similarly, operating personnel should be aware of the importance of the ventilation system on CRD performance.

\section{Components}

The integrity of the control rod drive system cables located in containment can be improved by using higher temperature rated assemblies. Several plants have upgraded their cable system to Tefzel insulation with a chlorosulfonated polyethylene jacket rated at $194^{\circ} \mathrm{F}$. Other cable systems offered for the CRDM's are rated as high as $1000^{\circ} \mathrm{F}$.
The coils are designed for a temperature of $400^{\circ} \mathrm{F}$. It is not clear why the stationary gripper coils are failing at a much higher rate than the movable or lift coils. The only apparent difference is that current $(4.4 \mathrm{~A})$ is continuously applied to the stationary gripper coil to hold the control rods in position. The ohmic heating generated may contribute to the cable's degradation.

Monitoring the CRD system electrical integrity is justified based on its safety significance and operational performance. It is recommended that a current signature analysis technique being used at one plant be evaluated by other utilities. With this technique, each coil current is traced during rod motion. Analysis of the recorded data determines the acceptability of the power and logic circuitry and the coil integrity. In addition, a rough indication of mechanical interferences can be ascertained.

A common maintenance practice of measuring the resistances of cables, connectors, and coils at regulated conditions (baseline temperature) is also recommended following each refueling. Measurements of the loop inductance or dissipation factor may also be beneficial in monitoring degradation.

\section{REFERENCES}

[1] W. Gunther and K. Sullivan, "Aging assessment of the Westinghouse PWR Control Rod Drive System," NUREG/CR-5555. Mar. 1991.

[2] J. Vora, "Nuclear Plant Aging Research (NPAR) Program," NUREG-1144, Rev. 1, Sept. 1987.

[3] J. Miyaguchi, "Development of a PWR CRDM data analyzing system" in Trans. 1989 Winter Meet., Amer. Nucl. Soc. (ANS), Mitsubishi, Kobe, Japan, Nov. 1, 1989. 